\title{
SYNTHESIS, ANTIBACTERIAL AND ANTIFUNGAL INVESTIGATIONS OF MN (II) COMPLEXES WITH SCHIFF BASES DERIVED FROM 2 - HYDROXY - 1 - NAPHTHALDEHYDE AND SOME ALIPHATIC DIAMINES
}

\author{
Aliyu H. N. and Sani U. \\ Department of Pure and Industrial Chemistry, Bayero University, Kano. P. M. B. 3011 Kano State Nigeria. \\ nababaagwa@yahoo.com
}

\begin{abstract}
Schiff base ligands derived from 2-hydroxy-1-naphthaldehyde and some aliphatic diamines were synthesized and characterized. Each of the ligands was used to form complex with Mn (II). Solubility, elemental analyses and IR spectra were carried evaluated. Elemental analyses of the complexes for $C, N$ and $H$ revealed 1:1 metal to ligand ratio. Antibacterial and antifungal activities were determined. Disc diffusion method was employed for these antimicrobial assays against four pathogenic bacteria (Escherichia coli, Salmonella typhi, Proteus sp. and Klebsiella pneumonae) and two fungi (Mucor sp. and Rhizopus sp.). It was found that the ligands and the complexes showed different activities against the isolates. The complexes showed higher activity than the free ligands.
\end{abstract}

Keywords: Schiff base, diamine, ligand, complex, isolates, analysis

\section{INTRODUCTION}

Addition of an amine to a compound containing a carbonyl functional group aldehyde or ketone, produces an imine, which is also known as a Schiff base. The former gives an aldimine while the latter produces a ketoimine. The resulting Schiff base can be an effective coordinating ligand if it bears an additional group usually a hydroxyl group near the site of condensation. A Schiff base acts as a ligand because it usually contains $-\mathrm{N}$ and $-\mathrm{O}$ donor atoms (Cotton and Wilkinson, 1972).

The earliest systematic synthetic study of Schiff bases was initiated by Pfeiffer et al. (1931). They prepared a variety of complexes derived from salicyldehyde and pyrrole -2- aldehyde. Much work has been reported on transition metal complexes of Schiff bases derived from suitably substituted aromatic carbonyl compounds and a number of amines (Alev et al, 2004, Jeong- Geun and Yong - Koo, 1999). However, exhaustive literature search revealed paucity of information on transition metal complexes of aromatic Schiff bases derived from aliphatic diamines and aromatic compounds such as 2-hydroxy-1naphthaldehyde. One of the available works suggested the formation of $\mathrm{N}, \mathrm{N}^{`}$-bis (2-hydroxy-1naphthyl) ethylenediiminato copper (II) complex during attempted preparation of copper (II) mixed chelates from dibasic Schiff base (Ahmed and Akhtar, 1986).

Chelate compounds obtained from Schiff bases are convenient for the study of change in structure and associated biological activity, since varying the substituents in the metal ring permits variation in the three dimensional structure of the molecule (Eman et al., 2008). It has been demonstrated through several studies that biological activity of chelating compounds is enhanced on chelation with metal ions. Some of the inactive ligands have been found to develop such properties upon chelation (Eman et al., 2008). The antitumor activity of some Schiff bases has been attributed to their ability to chelate with transition metals. Several explanations have been suggested for this enhancement. Generally, it has been observed that certain transition metal complexes have greater activity and less toxic effects than the free ligand (Eman et al., 2008). The azomethine linkage is a significant feature that makes Schiff base ligands interesting candidate for biological activity as well as coordination/chelation with the metal ions (Sari et al., 2003, Cimerman et al,, 2000, Spinu and Kriza, 2000). The interaction between metal ions and such biologically active ligands represents an important route in designing new metal-based antibacterial, antifungal and anticancer therapies against different kinds of bacteria, fungi and viruses that are resistant to the conventional drugs.

Schiff base aldehydes have a wide variety of applications in many fields e.g. biological, industrial and analytical (Ibrahim and Sherif, 2007). Schiff bases derived from acetylacetone and p-methoxyaniline showed great activity against some bacteria like Staphylococus aureus, Bacillus sutilis, Escheriachia coli and fungi, Aspergillus niger (Ramon et al., 2003). They can as well be used as fluorimeric analytical reagents (Ibrahim and Sherif, 2000, Cimerman et al., 2000). Transition metal Schiff base complexes play very vital roles as they are known to possess biological activities such as anticonvulsant, antibacterial, antiviral and antidiabetic (Mimose et al., 1991). Sudo et al. (1997) reported that rhodonine derivatives acted as hepatitic $\mathrm{C}$ virus (HCV) protease inhibitor. It was reported that transition metal Schiff base complexes could be used as corrosion inhibitors as well as antifungal and antifouling agents (Bhatia et al., 1993). 
Moreover,

2-hydroxy-1-naphthaldehyde thiosemicarbazone complexes with $\mathrm{Co}(\mathrm{II}), \mathrm{Ni}(\mathrm{II})$, $\mathrm{Zn}$ (II) and $\mathrm{Cu}$ (II) were reported to be biomimic enzyme catalysts (Ming et al., 2000). Byeong - Goo et al. (1996) reported a new synthetic procedure for the preparation of some copper (II) complex compounds from condensation of copper (II) acetate and prepared Schiff bases derived from 2-hydroxy-1naphthaldehyde and some aliphatic diamines.

However, microbial activity of the Schiff bases and their complexes were not studied, which this paper presents.

\section{MATERIALS AND METHOD}

All chemicals and solvents used were of analytical grade (AnalaR or BDH) while 2-hydroxy-1naphthaldehyde and diamines were obtained from Sigma-Aldrich and were used without further purification. Molar conductance measurements were carried out using Jenway 4010 conductivity meter. Elemental analyses for carbon, nitrogen and hydrogen were carried out at the Micro-analytical Laboratory at the University of Bristol, United Kingdom. Four pathogenic bacteria viz: Klebsiella sp., Escherchia coli, Proteous sp. and Salmonella $s p$. and two fungi Rhizopus sp., Mucor $s p$. were collected from Microbiology Unit of the Department of Biological Sciences, Bayero University, Kano, Nigeria. Nutrient agar and Potato Dextrose agar were used as bacteriological and fungal media respectively.

\section{Preparation of the Ligands}

All the ligands were prepared as described by Ahmed and Akhtar (1986), Beong - Goo et al. (1996). The ligands formed were then filtered, washed with ethanol and dried over phosphorus pentoxide for a week.

\section{Preparation of the complexes}

All the complexes were prepared as described by Ahmed and Akhtar, (1986); Beong - Goo et al, (1996). They were separated, washed with ethanol and dried over phosphorus pentoxide for a week.

\section{Antibacterial Activity Test}

The ligands and complexes were dissolved separately in Dimethylsulphoxide (DMSO) to have three different concentrations $(500 \mu \mathrm{g}, 1000 \mu \mathrm{g}$ and $2000 \mu \mathrm{g})$ per disc. They were placed on the surface of the culture and incubated at $37^{\circ} \mathrm{C}$ for $24 \mathrm{hrs}$ following the method Bukhari et al., 2005; Ramon et al., 2003; Yeamin et al, 2003. The in vitro antibacterial activity was carried out by disc diffusion method. The diameter of zone of inhibition produced by the ligands and complexes were compared with Augumentin $(30 \mu \mathrm{g})$ and Ketoconozole $(600 \mu \mathrm{g})$ for bacterial and fungal standard respectively.

\section{RESULTS AND DISCUSSION}

The resulting ligands appeared crystalline solids. The percentage yield recorded was 75.50 - 89.17 as shown in Table 1 . Solubility test carried out on the ligands in some common solvents showed that, they were soluble in methanol, ethanol and DMSO but insoluble in water, ether and carbon tetrachloromethane while slightly soluble in nitrobenzene and acetonitrile. The complexes are readily soluble in DMSO only. Molar conductivity values of the complexes in DMSO solution were in the range $9-12 \Omega^{-1} \mathrm{~mol}^{-1} \mathrm{~cm}^{2}$ confirmed the nonelectrolytic nature of the complexes.

All the ligands and complexes were characterized by elemental analyses to determine percentage of $\mathrm{C}, \mathrm{N}$ and $\mathrm{H}$. The observed and calculated compositions (\%) of the elements were in good agreement and supported the one ligand to a metal ion complexation as shown in Table 1 and Fig. 2.

The antibacterial activity test for the ligands and the complexes were determined. The diameter of inhibition zone $(\mathrm{mm})$ was measured for each treatment. The ligands showed minimal activity against the entire organisms (Table 3 ) with no activity recorded against Klebsiella pneumonae. However, Salmonella typhi. is resistant to [MnL'] at all the concentrations $L^{\prime}$ is $N, N^{\prime}$ - bis (2-hydroxy-1naphthyl) ethylenediiminato. while [MnL“'] resistant at 1000 and $20000 \mu \mathrm{g}$ where is $\mathrm{L}^{\prime} \mathrm{N}, \mathrm{N}$ - - bis (2hydroxy-1-naphthyl) propylenediiminato . [MnL ' '] is found to be active at all the concentrations where $\mathrm{L}^{\prime}$ ' is $\mathrm{N}, \mathrm{N}$ ' - bis (2-hydroxy-1-naphthyl) butylenediiminato. The complexes showed stronger activity on the isolates. Highest zone of $10 \mathrm{~mm}$ was recorded on Protueus sp. while $E$. coli showed $8-10$ $\mathrm{mm}$, with no activity on Kleb. In the case of [MnL ' '] $k / e b$ was resistant to it with some activity between 8 $15 \mathrm{~mm}$. Moreover, [MnL'”] showed similar result on the isolates as in the case of [MnL '] as shown in Table 4. All results were better than that obtained with the standard. This showed that the ligands and the complexes were more active than the standard.

Antifungal activities of ligand Schiff bases were studied and results presented in Fig1. The ligand L" recorded activities in three different concentrations against Mucor $s p$. with no activity on Rhizopus $s p$. while other ligands $L^{\prime \prime}$ and L'” recorded some

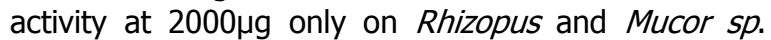
Antifungal activity for the complexes (Table 6) showed that [MnL'] was active on Rhizopus sp. and Mucor sp. at $1000 \mu \mathrm{g}$ and $2000 \mu \mathrm{g}$ respectively while [MnL'”] gave no zone of inhibition. But for [MnL' ' '], it was active on Rhizopus. $s p$. at all concentrations while Mucor sp. produced some activity at $1000 \mu \mathrm{g}$ and $2000 \mu \mathrm{g}$. The results indicated that the complexes showed more activity than the ligands under similar experimental conditions. This would suggest that the chelation could facilitate the ability of a complex to cross a cell membrane which can be explained by Tweedy's chelation theory (Fehmi et al., 1998). Chelation considerably reduces the polarity of the metal ion mainly because of partial sharing of its positive charge with the donor groups and possible electron delocalization over the whole chelate ring. Such chelation could also enhance the lipophilic character of the central metal atom, which subsequently favors its permeation through the lipid layer of the cell membrane (Tumer et al., 2007) 
Bajopas Volume 4 Number 1 June, 2011

Table 1: Some Physical Properties of the Ligand and Mn(II) Schiff Base Complexes

\begin{tabular}{llccc}
\hline Ligands/Complexes & Colour & \% Yield & $\begin{array}{l}\text { Melting Point } \\
\left({ }^{\circ} \mathbf{C}\right)\end{array}$ & $\begin{array}{c}\text { Decomposition } \\
\text { Temp. }\end{array}$ \\
\hline L' $\left.{ }^{\circ} \mathbf{C}\right)$
\end{tabular}

$\mathrm{L}^{\prime}=\mathrm{N}, \mathrm{N}^{\prime}$ - bis (2-hydroxy-1-naphthyl) ethylenediiminato

$\mathrm{L}^{\prime}$ ' = N, N' - bis (2-hydroxy-1-naphthyl) propylenediiminato

$L^{\prime}{ }^{\prime}=N, N^{\prime}$ - bis (2-hydroxy-1-naphthyl) butyllenediiminato

[MnL'] = N, N` - bis (2-hydroxy-1-naphthyl) ethylenediiminato Manganese (II)

$\left[\mathrm{MnL}^{\prime}{ }^{\prime}\right]=\mathrm{N}, \mathrm{N}$ ' - bis (2-hydroxy-1-naphthyl) propylenediiminato Manganese (II)

$\left[\mathrm{MnL}^{\prime}{ }^{\prime}\right]=\mathrm{N}, \mathrm{N}$ ' - bis (2-hydroxy-1-naphthyl) butylenediiminato Manganese (II)

Table 2: Elemental Composition of the Ligands and their Complexes

\begin{tabular}{lccc} 
& \multicolumn{3}{c}{ Percentage Calculated (Found) } \\
\hline Ligands/Complexes & C & H & N \\
\hline $\mathrm{L}^{\prime}$ & $78.33(78.15)$ & $5.48(5.40)$ & $7.61(7.33)$ \\
$\mathrm{L}$ & $78.61(78.48)$ & $5.81(5.54)$ & $7.33(7.13)$ \\
$\mathrm{L}^{\prime}$ & $78.86(78.81)$ & $6.11(6.10)$ & $7.07(7.01)$ \\
{$\left[\mathrm{MnL}^{\prime}\right]$} & $68.42(65.78)$ & $4.31(4.27)$ & $6.65(6.29)$ \\
{$\left[\mathrm{MnL}^{\prime}{ }^{\prime}\right]$} & $69.04(6.01)$ & $4.64(4.55)$ & $6.44(6.44)$ \\
{$\left[\mathrm{MnL}^{\prime}\right]$} & $64.21(63.21)$ & $4.94(4.80)$ & $6.24(6.01)$ \\
\hline
\end{tabular}

Table 3: Sensitivity of Clinical Isolates to the Ligands

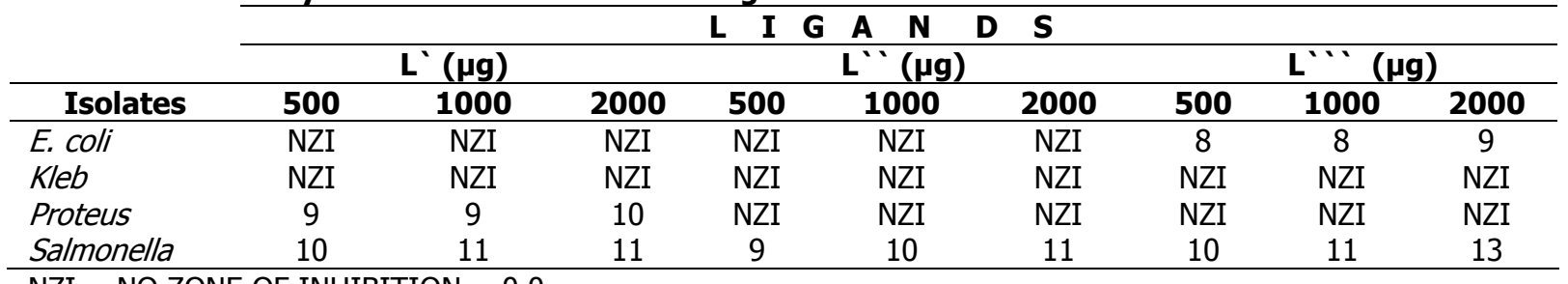

$\mathrm{NZI}=$ NO ZONE OF INHIBITION $=0.0$

Table 4: Sensitivity of Bacterial Pathogens on Mn(II) Schiff base Complexes

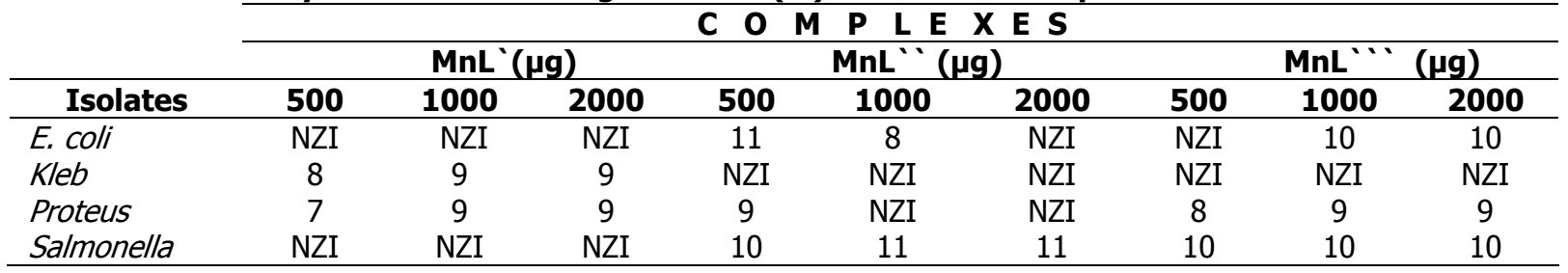

Table 5: Sensitivity of Fungal Isolates to Ligands

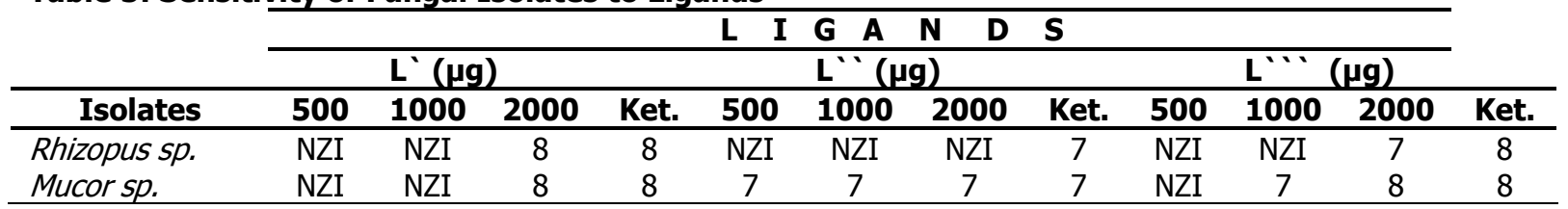

Ket. $=$ Ketoconozole

Table 6: SensitivityTests of Fungal isolates to Cobalt (II) complexes

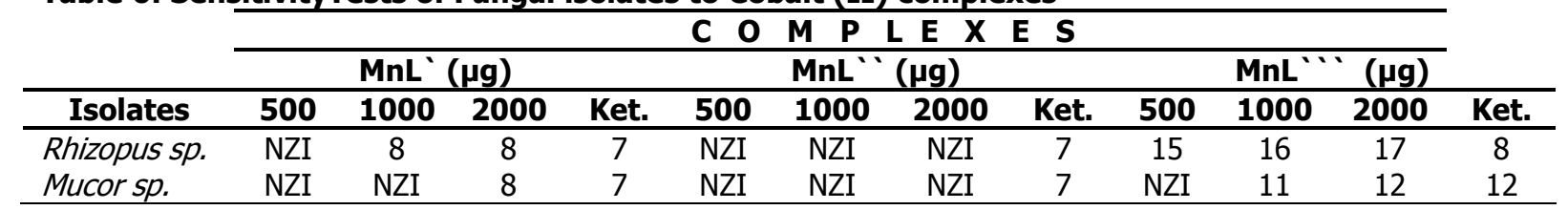




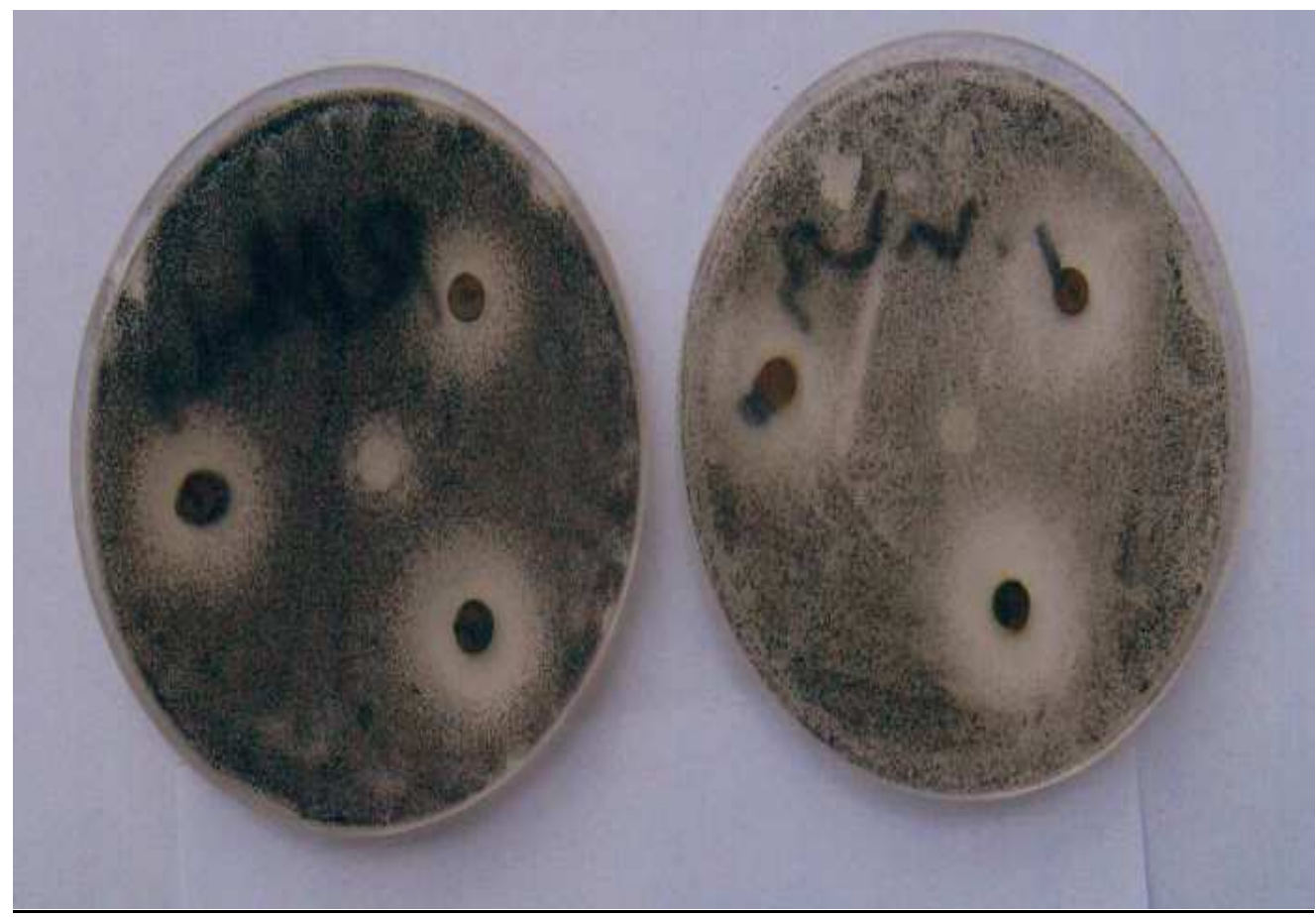

Fig. 1: Antifungal Activity of the complexes against Rhizopus and Mucor

From the results of the analyses carried out on the complex compounds and the earlier report on similar work, the general molecular formula below is suggested.<smiles>c1ccc2c(c1)CN[C@]1(Cc3ccccc3O1)O2</smiles>

Fig. 2: Proposed General Molecular Structure of the Mn(II) Schiff Base Complex Compounds

\section{REFERENCES}

Ahmed, A and Akhtar F (1986): Cu (II) and Ni(II) complexes with a tetradentate Schiff base derived from 2-hydroxy-1-naphthaldehyde and ethylenediamine, Indian Jour Chem. 20A, pp 737-758

Alev, D., Sakiyan, I. and Kilic, E. (2004): Potetiometric Studies on Some a-amino Acid Schiff Bases and Their manganese (III) Complexes in Dimethyl Sulphoxide - water Mixture at $25^{\circ} \mathrm{C}$, Journal of Solution Chemistry, vol. 33, No. 12, pp 1539 - 1547

Anjelici R.J. (1971): Synthesis and Techniques in Inorganic Chemistry, W. B. Saunders Company, Philadelphia, $2^{\text {nd }}$ edition pp 115 125
Bukhari, I. H., Arif, M., Akbar J. and Khan, A. H. (2005): Preparation, Characterization and Biological Evaluation of Schiff Base Transition Metal Complexes with Cephreadine, Pakistan Journal of Biological Sciences, 8(4), pp 614 617

Bhatia P. K., Guar Y.D. and Rao N. S. S. (1993): Hydrogen uptake among fast and slow growing nitoza, Bradyrihizbia nodalation pigeonpea cultivars, Plant Physiol. Biochem., $19,30-32$

Byeong-Goo J., Chae-Pyong R., Hee-Nam C, Ki-Hyung C. and Yohng-Kook C (1996): Synthesis andCharacterization of Schiff base derived from 2-hydroxy-1-naphthaldehyde and Aliphatic Diamines Bull. Korean Chem. Soc. vol 17, no8, pp $687-693$ 
Cimerman Z., Miljanie S. and Galic N. (2000): Schiff bases derived from Aminopyridines as spectrofluometric Analytical Reagents, CROATICA Chemica Acta. 73, 81

Cotton F. A. and Wilkinson G. (1972): Advanced Inorganic Chemistry, Interscience Pub. New York, $3^{\text {rd }}$ Edition, p 624

Eman A.E., Khaleed H.H., Safan K.H. and Nabil S.Y. (2008): Synthesis, Characterization and Biological activity of Transition metal complexes with Schiff bases derived from 2Formylindole, Salicyldehyde and $\mathrm{N}$-amino rhodanine, Austrialian Jour. of Basic and Applied sciences, 2(2), $210-220$

Mimose Y. K., Meguro H., Ikeda C. Hatanaka S. and Sohda T. (1991): Studies on Antidiabetic Agents, Synthesis and Biological Activity of Pioglitazone and related compounds, Chem. Pharm. Bull., 39, 1440

Ming D. U., Fang Z. L., Bo T., Yun Jing L., Han Xi S., Bin T. and Yan L. (2000): Metal-2- hydroxyl1-naphthaldehyde Thiosemicarbazone complexes, Chinese Chemical Letters, vol. 11 No. $123-26$

Mohammed, N. I.. and Sheriff, S. A. (2007): Synthesis, Characterization and Uses of Schiff Bases as Fluorimeric Analytical Reagents, EJournal of Chemistry, www.e-journals.net, vol. 4, No. 4, pp $531-535$

Nakamoto K. (1978): Infrared and Ramon Spectra of Inorganic and Coordination Compounds, John Wiley and sons Inc. New York

www.pubmedcentral.nih.gov/artclerender.fcgi (2008): Synthesis, Biological, Spectral and Thermal Investigations of $\mathrm{Co}(\mathrm{II})$ and $\mathrm{Ni}$ (II) complexes

Pfieffer P., Bucholt E. and Baumer O. (1931): Inner Complex salts from Hydroxy aldimines and hydroxyl ketoimines, J. Prakt. Chem. 129, $163-177$
Ramon N., Mutijuraj V., Rovichandran S. and Kulandaisamy A. (2003): Synthesis, Characterization and Electrochemical Behavior of $\mathrm{Cu}(\mathrm{II}), \mathrm{Co}(\mathrm{II}), \mathrm{Ni}(\mathrm{II})$ and $\mathrm{Zn}$ (II) complexes derived from acetylacetone and p-anisidine and their antimicrobial activity, Proc. Ind. Acad. Sci., vol. 115, no. 5, pp 161 $-167$

Rist G. H., Hyde J. S. and Vanngard T. (1970): Electron-nuclear double resonance of a protein that contains Copper Evidence for Nitrogen Coordination to $\mathrm{Cu}(\mathrm{II})$ in Stellcyamin, Natl. Acd. Sci. 1, 67

Sari N., Arslan S., Logoglu E. and Sakiyan L. (2003): Antibacterial Activities of Some new Amino acid Schiff bases, G.U. J. Sci., 16(2), 283 288

Spinu, C and Kirza A. (2000): Co(II), Ni(II) and Cu(II) complexes of Bidentate Schiff bases, Acta Chim. Slov., 47, 179

Sudo K., Masumoto Y., Mastushima M., fajwara M., Kunno K., Shimatohno K., Shigerta S. and Yokora T. (1997): Novel Hepatitis C virus Protease Inhibitors Thiozolidine Derivatives, Biochem. Biophys. Res. Comm., 238, 643 647

Tumer, M.; Ekinci, D.; Tuner, F. and Bulut A. (2007): Synthesis, Characterization and Properties of some of some divalent metal (II) complexes: Their electrochemical catalytic, thermal and antimicrobial activity studies, Spectrochemica Acta, Part A: Molecular and Biomolecular Spectroscopy, 67(3-4), pp 916

Yeamin R. Belayet H. and Saidul Islam M. (2003): Antimicrobial Studies of Mixed Ligand Transition Metal Complexes of Phthailc acid and heterocyclic amine bases, Pakistan $\mathrm{J}$. Biological Sciences, 6(17), 1494 - 1496 